hazard that has received little attention in medical reports.

We found an increased vulnerability to burglary among elderly people. The main factors underlying this phenomenon are social isolation, poor mobility, little use of security equipment, and an overtrusting attitude to callers. Elderly victims report particularly high objective (medical attention, decreased mobility, social disruption) and subjective (psychological burden) markers of stress and illness after burglary. The violation of the home seems to be particularly distressing: the home assumes increased importance with decreasing mobility and reduced social contacts.

This problem must be approached in a comprehensive manner by those concerned with health and housing services for elderly people. Doctors and other health care staff should provide identification at the first domiciliary visit and should not encourage such practices as leaving doors open for community health workers. Emphasis on security alone, however, may lead to a siege mentality and further isolation. Preventive measures such as education in schools, reconsideration of community policing policy, and increased public awareness will also be necessary. A prerequisite is the recognition of burglary and vandalism as important additional environmental hazards for elderly people living in the community.

1 Coakley D, Woodford-Williams E. Effects of burglary and vandalism on the health of old people. Lancet 1979;ii: 1066-7.

2 Alston L. Crime and older Americans. Springfield, Illinois: Charles C Thompson, 1986:78.

3 Royal College of Physicians of London. Report of the committee on accidental hypothermia. London: RCP, 1966.

4 Kelly I, Clancy L. Mortality in a general hospital and urban air pollution. Ir Med f 1984:77:322-4.

5 McAvoy B. Death after bereavement. Br.Med f 1986;293:835-6

(Accepted 5 April 1989)

\section{Incidence and intensity of postpartum lower abdominal pain}

\author{
Angela Murray, Anita Holdcroft
}

\section{Department of}

Anaesthetics, Royal

Postgraduate Medical

School and Hammersmith

Hospital, London

W12 0NN

Angela Murray, FFARCS, senior registrar

Anita Holdcroft, FFARCS, senior lecturer and honorary consultant

Correspondence to: $\mathrm{Dr}$ Holdcroft.

Br.Med J 1989;298:1619

Total pain.rating index scores ${ }^{\star}$ in primiparous and multiparous women complaining of postpartum lower abdominal pain

\begin{tabular}{lcc}
\hline $\begin{array}{c}\text { Total } \\
\text { pain } \\
\text { rating } \\
\text { index } \\
\text { score }\end{array}$ & $\begin{array}{c}\text { No of } \\
\text { primiparous } \\
\text { women } \\
(\mathbf{n}=50)\end{array}$ & $\begin{array}{c}\text { No of } \\
\text { multiparous } \\
\text { women } \\
(\mathbf{n}=86)\end{array}$ \\
\hline $0-$ & 8 & 19 \\
$6-$ & 10 & 11 \\
$11-$ & 14 & 14 \\
$16-$ & 9 & 17 \\
$21-$ & 4 & 8 \\
$26-$ & 1 & 8 \\
$31-$ & 2 & 5 \\
$36-$ & 1 & 2 \\
$41-$ & 1 & 2 \\
$46-50$ & & \\
\hline Mean & \\
(SF) & \\
score & $15 \cdot 4(1 \cdot 5)$ & $16 \cdot 1(1 \cdot 1)$ \\
\hline Based on McGill pain \\
questionnaire with rank order \\
scores.
\end{tabular}

During labour women may experience lower abdominal pain related to the uterine contractions. In the postpartum period pain may persist but not be so severe. Mild analgesics are often used to relieve this,' but at times they are inadequate. We determined the incidence and intensity of postpartum lower abdominal pain in relation to precipitating and relieving factors.

\section{Patients, methods, and results}

One hundred primiparous and 100 multiparous women were interviewed with a standard questionnaire up to 48 hours after vaginal delivery. Fifty of the primiparous and 86 of the multiparous women complained of lower abdominal pain $(p<0.001)$. Periodic pain occurred in $49(98 \%)$ and $79(92 \%)$ of these primiparous and multiparous women respectively, and it was almost twice as frequent in the multiparous compared with the primiparous women. Back pain was associated with the lower abdominal pain in half the women.

The maximum intensity of the pain was scored by the mothers with a simple word score, a visual analogue score, and the McGill pain questionnaire. ${ }^{2}$ Severe and moderate pain occurred in 30 primiparous and 58 multiparous women. The visual analogue scores showed a skewed distribution with the mode in the primiparous women being $2-3 \mathrm{~cm}$ and that in the multiparous women $4-5 \mathrm{~cm}$. The table shows the results of the McGill pain questionnaire. The words used most commonly to describe the pain were throbbing, cramping, and aching. The pain was described as sharp by $11(22 \%)$ primiparous women compared with 30 (35\%) multiparous women.

The pain was relieved by a change in position, sleep, and oral analgesics in half the women in both groups; by passing urine in a quarter of the women in both groups; and by physiotherapy exercises in $20(40 \%)$ primiparous women compared with $14(16 \%)$ multiparous women $(\mathrm{p}<0 \cdot 01)$. Breast feeding exacerbated the pain in $48(96 \%)$ of the primiparous women and 70 $(81 \%)$ of the multiparous women.
Multiparous women were asked if they had had similar pain in previous pregnancies. About half of the women with one other child could not remember having had postpartum pain. Mothers of two and more children could almost always recall a similar pain that had tended to increase in severity with each labour. Individual effects of ethnic origin (either European or West Indian and African descent), epidural analgesia, oxytocic drugs, and method of feeding the baby on the incidence of lower abdominal pain showed no significant difference between the two groups.

\section{Comment}

After delivery the incidence of lower abdominal pain was significantly higher in multiparous women than primiparous women $(\mathrm{p}<0.001)$ despite less surgical intervention. The pain is probably uterine in origin as it is central and intermittent, such as would originate from a muscular viscus, and exacerbated by breast feeding. It was more severe in multiparous women as scored by a word scale and visual analogue scale. The McGill pain questionnaire scores were similar in the two groups, of a severity between that of menstrual and labour pains, ${ }^{34}$ but up to $10 \%$ of women who had experienced pain had a total pain rating index score of above 30 , which is as severe as that recorded in labour.

The McGill pain questionnaire showed a difference between the groups in the affective category of tiredness. This may reflect the longer duration of the first stage of labour in primiparous women, and sleep was a relieving factor. The use of exercises and change of position requires further evaluation because in primiparous women they gave greater relief than expected. The severe pain observed in some of the women requires to be identified and supportive treatment given.

We thank Dr Mal Morgan for his advice and criticism; and the consultant obstetricians at the Royal Postgraduate Medical School for allowing us to interview their patients; and Miss Beverly Williams for secretarial help.

I Bloomfield SS, Cissell GB, Mitchell J, Barden TP. Codeine and aspirin analgesia in postpartum uterine cramps: qualitative aspects of quantitative assessments. Clin Pharmacol Ther 1983;34:488-95.

2 Melzack R. The McGill pain questionnaire: major properties and scoring methods Pain 1975;1:27799.

3 Niven C, Gijsbers K. A study of labour pain using the McGill pain questionnaire. Niven C, Gijsbers K. A study of labou
Soc Sci Med 1984;19:1347-51.

4 Melzack R, Taenzer P, Feldman P, Kinch RA. Labour is still painful after prepared childbirth training. Can Med Assoc $\mathcal{F}$ 1981;125:357-63.

(Accepted 10 April 1989) 